\title{
A Adaptação da Sonata em Dó Menor para Cistre e Baixo Contínuo de Francesco Geminiani (1760) para Viola de Arame
}

\section{The Adaptation of the Sonata in C minor for Cistre and Continuous instrument by Francesco Geminiani (1760) for Wire Baroque Guitar}

iD Luciano Hercílio Alves Souto

(Universidade do Estado do Amazonas, Programa de Pós-graduação em Letras e Artes, Laboratório de Musicologia e História Cultural. Manaus, AM, Brasil.) (Universidade Estadual Paulista Júlio de Mesquita Filho, Programa de Pós-graduação em Música, Instituto de Artes, São Paulo, SP, Brasil.) Isouto@uea.edu.br

Resumo: Este artigo discute a adaptação da sonata em dó menor para cistre e baixo contínuo de Francesco Geminiani (1760) para viola de arame, com o objetivo de investigar parâmetros críticos, analíticos e transcritivos fundamentais para tal procedimento. Aborda elementos que necessitam ser avaliados na mudança de meio notacional e instrumental, como técnica, tonalidade, afinação, harmonia, articulação, ornamentação e dinâmica, à luz de fontes primárias e secundárias como Geminiani (1749-1760), Leite (1764), Sanz (1674), Ribeiro (1789), Cardoso (2014), Costa (2012) e Tyler (2011). Os resultados propiciaram performances contextualizadoras do pensamento musical de Geminiani em relação à prática instrumental de época.

Palavras-chave: Francesco Geminiani. Sonata em dó menor. Instrumento de Corda. Transcrição.

Abstract: This paper discusses the transcription of the sonata in C minor for cistre and continuous bass by Francesco Geminiani (1760) for wire baroque guitar, with the objective of investigating critical, analytical and 
transcriptive parameters essential for its adaptation. It addresses elements that need to be evaluated when changing notational and instrumental mediums such as technique, tonality, tuning, harmony, articulation, ornamentation and dynamics, in the light of primary and secondary sources such as Geminiani (1749-1760), Leite (1764), Sanz (1674), Ribeiro (1789), Cardoso (2014), Costa (2012) and Tyler (2011). The results provided contextualizing performances of Geminiani's musical thought in relation to the instrumental practice of that time.

Keywords: Francesco Geminiani; Sonata in C minor; String Instrument; Transcription.

Submetido em: 11 de agosto de 2020

Aceito em: 16 de outubro de 2020 
A Adaptação da Sonata em Dó Menor para Cistre e Baixo Contínuo de Francesco Geminiani... Luciano Hercílio Alves Souto

\section{Introdução}

A historiografia das cordas dedilhadas apresenta lacunas no que concerne à inserção do cistre e de seu repertório nas discussões sobre a organologia, os sistemas de codificação, as técnicas de execução e sobre o repertório deste instrumento e sua relação com a viola de arame, embora autores como Silva Leite (1764) e outros tenham tocado e escrito para ambos os instrumentos. As pesquisas realizadas por Nogueira (2008) sobre a viola de arame constatam que esse instrumento pertence à família das guitarras e, por este motivo, incorpora uma ampla produção musical dos séculos XVII e XVIII pertencente aos demais instrumentos da mesma família. No entanto, o aproveitamento do repertório do cistre pela viola de arame ainda carece de investigação, considerando suas semelhanças morfológicas, notacionais e técnico-idiomáticas em vista da falta de quaisquer referências sobre o compartilhamento de repertório entre esses dois instrumentos, conforme se pode constatar entre os demais instrumentos da família das cordas dedilhadas.

A Sonata em dó menor para cistre com acompanhamento de baixo contínuo para violoncelo ou cravo de Francesco Geminiani (1687-1762) constitui o Example // de uma coletânea de onze exemplos musicais em forma de sonata, publicados no tratado The Art of Playing the Guitar or Cittra (1760), de autoria do compositor. 
A Adaptação da Sonata em Dó Menor para Cistre e Baixo Contínuo de Francesco Geminiani... Luciano Hercílio Alves Souto

Figura 1 - Frontispício

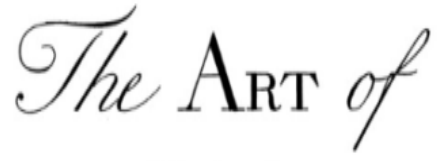

Playing the

\section{Guitar or Cittra}

Containing

Several bompositions with a BAss for che

VIOLONCELLO or HARPSICHORD

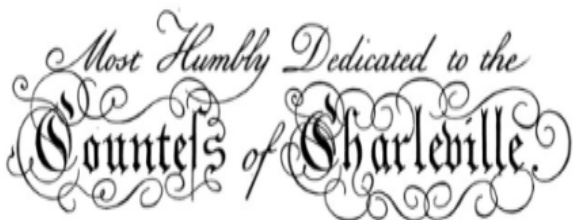

by

Ff. Geminiani?

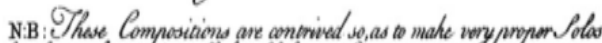
for the Violin; and as all the Shifsu and Grans nquisits to play in a good taste are distinctly mart dil it must le of grat use to those nhe aspure to play that Inomument,

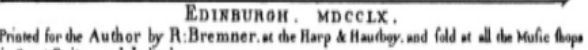
Greas Brition and Jreload:

GEMINIANI, Francesco. 1760, frontispício Frontispício do The Art of Playing The Guitar or Cittra (1760)

Os exemplos contidos no tratado publicado em Edimburgo (Escócia) se encontram dispostos nas tonalidades homônimas maiores e menores a partir de dó (maior e menor), ré (maior e menor) e assim sucessivamente até o $11^{\circ}$ e último exemplo em lá maior. $\mathrm{O}$ exemplo musical $\mathrm{n}^{\circ} \| \mathrm{l}$ abordado por este trabalho se divide em cinco movimentos: I - Andante/Allegro, II - Andante, III Allegro Cantábile, IV - Allegro/Grave/Allegro e V - Allegro Moderado. A Figura 2 corresponde ao primeiro movimento (Andante), compassos 1 a 9 . 
A Adaptação da Sonata em Dó Menor para Cistre e Baixo Contínuo de Francesco Geminiani... Luciano Hercílio Alves Souto

Figura 2 - Exemplo musical II: The Art of Playing the Guitar or Cittra (1760)

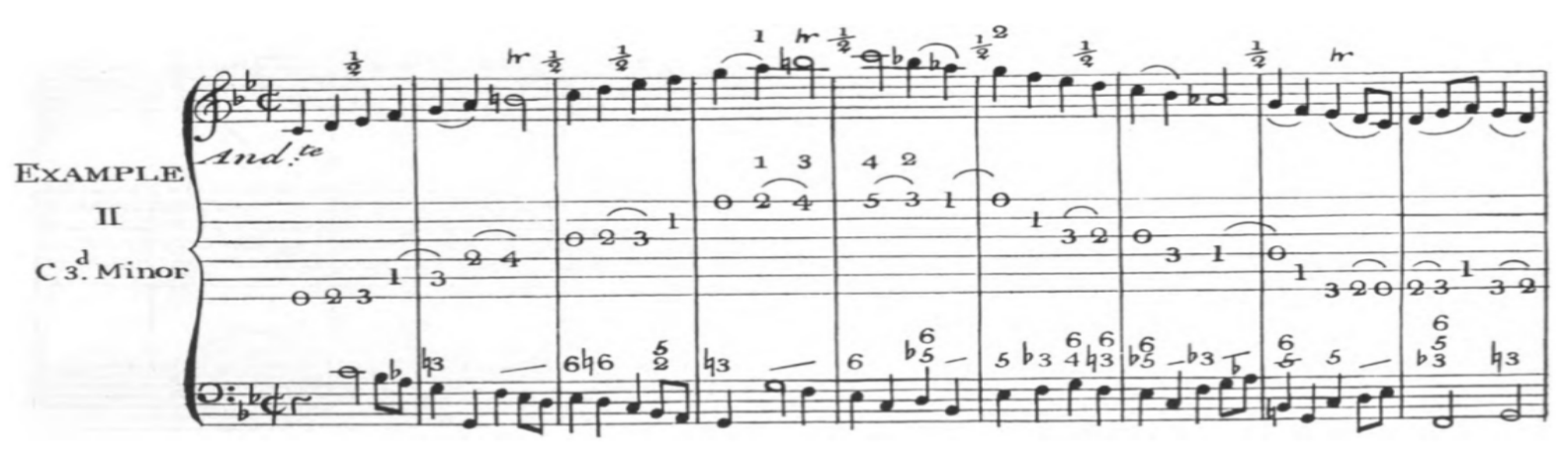

GEMINIANI, Francesco. 1760, p. 8.

Exemplo musical II, em dó menor, primeiro movimento.

A linha central correspondente à Guitarra ou Cittra é escrita em tablatura espanhola em razão da sua representação espacial das alturas corresponder aos registros agudo na parte superior e grave na parte inferior, utilizando-se de números representativos dos pontos no braço do instrumento que devem ser pressionados pela mão esquerda para a obtenção do som correspondente (NOGUEIRA, 2016). Sobre sua tablatura, Geminiani (1760) escreve:

A pauta central, que consiste de seis linhas, representa as seis cordas da guitarra. Quando 0 está posicionado em qualquer linha, denota que aquela corda deve ser tocada solta. Os demais números representam os trastes que cruzam o espelho, bem como os dedos apropriados para tocar esses trastes. O número 1, posicionado na segunda linha, significa que o primeiro dedo deve ser posicionado no primeiro traste da $2^{a}$ corda, que é a corda que aquela linha representa. Semelhantemente, o número 2 significa o $2^{\circ}$ dedo sobre o $2^{\circ}$ traste da $3^{a}$ corda, e assim por diante. Mas, se uma segunda sequência de números é posicionada sobre as seis linhas, então os números sobre as linhas denotam apenas os trastes, e aqueles acima assinalam os dedos adequados para tocar esses trastes. Quando os números - em qualquer quantidade - são escritos sobrepostos, indicam que as notas constituem 
A Adaptação da Sonata em Dó Menor para Cistre e Baixo Contínuo de Francesco Geminiani... Luciano Hercílio Alves Souto

um acorde e devem ser golpeadas todas de uma só vez. Esta linha oblíqua / significa o mesmo. Quando um traço (curvo) é posicionado sobre dois ou mais números, apenas a primeira [nota] deve ser golpeada, porque os dedos, na passagem de uns para outros, produzirão o som. No que concerne ao tempo e ao valor das notas, a parte do violino deve apenas ser observada. (GEMINIANI, 1760, p. 1, traduzido por NEVES, 2017, p. 466-468).

A "segunda sequência de números posicionada sobre as seis linhas" e os números sobrepostos indicativos da simultaneidade de execução dos acordes podem ser visualizados na Figura 3, compassos 57 e 58 finais do primeiro movimento.

Figura 3 - Exemplo musical II

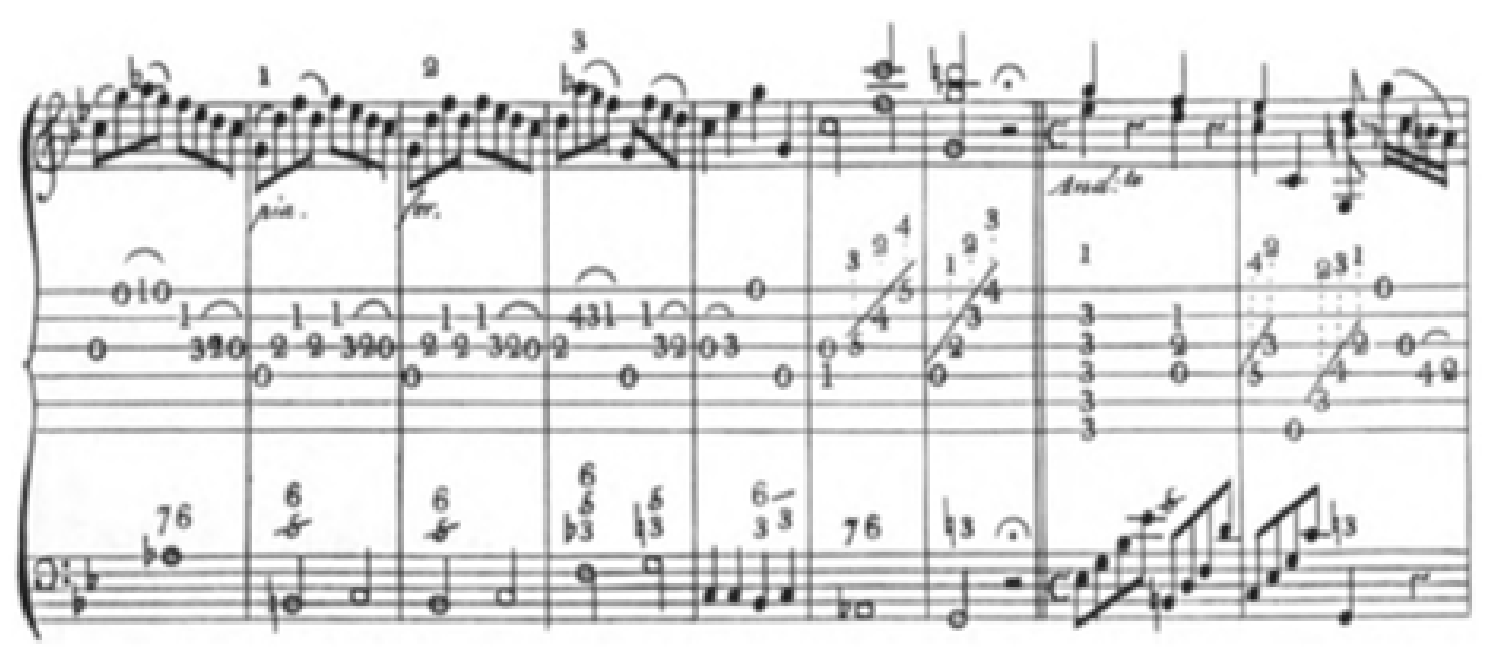

GEMINIANI, Francesco. 1760, p. 10.

Exemplo II, em dó menor, segundo movimento, compassos 57-58.

A parte de violino adquire importância considerável para a adaptação desta obra para viola de arame uma vez que reproduz a melodia do cistre e contempla notação específica para recursos expressivos diversos e ornamentos escritos não codificados na tablatura. Por outro lado, no que concerne à escrita harmônica, a tablatura apresenta acordes mais cheios do que aqueles notados 
A Adaptação da Sonata em Dó Menor para Cistre e Baixo Contínuo de Francesco Geminiani... Luciano Hercílio Alves Souto

na parte do violino. A Figura 4 representa os compassos 57 e 58,1 e 2 do primeiro e segundo movimentos respectivamente, correspondendo à cadência final do primeiro movimento.

Figura 4 - Exemplo musical II

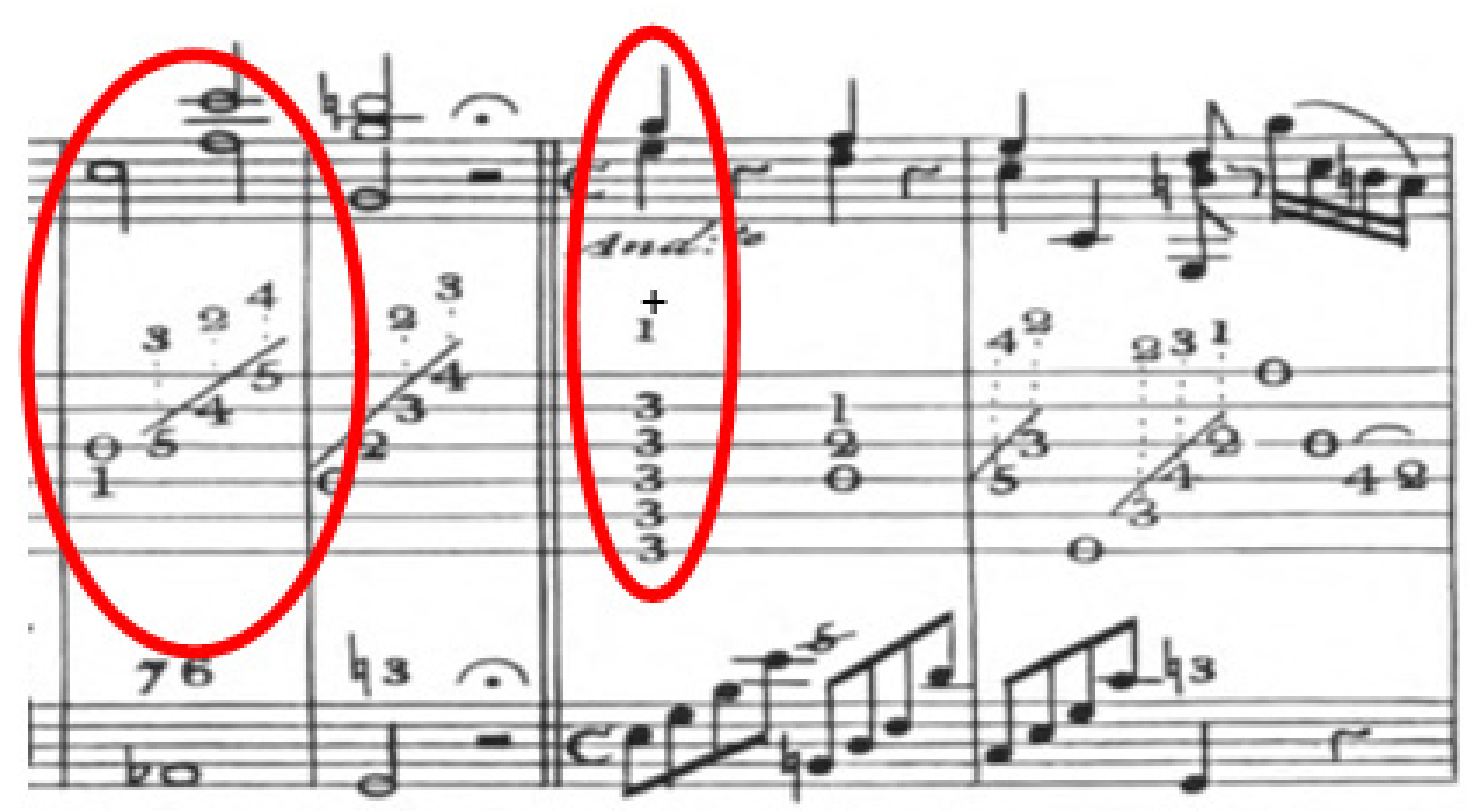

GEMINIANI, Francesco. The Art of Playing the Guitar or Cittra, 1760, p. 10

Exemplo I/ em dó menor, primeiro movimento, compassos 57 e 58; segundo movimento, compassos 1 e 2.

\section{Articulações e Ornamentos}

\subsection{Ligaduras}

Geminiani descreve as ligaduras de mão esquerda como um traço (curvo) posicionado sobre dois ou mais números. Tais recursos expressivos são utilizados pelos instrumentos de cordas dedilhadas, como guitarras e alaúdes, desde o século XVII, com função de articulação e ornamentação, sobre os quais Nogueira (2008, p. 107-108) escreve: "A ligadura, inexistente na notação do séc. XVI passa a ter significado de ornamento, então denominada Cheute e, mais adiante em Nicolas Deroisier, (Lês principes de la guitarre; 1696), Tirades (Tiratas) quando descendente; também 
A Adaptação da Sonata em Dó Menor para Cistre e Baixo Contínuo de Francesco Geminiani... Luciano Hercílio Alves Souto

Stracino em italiano e Extrasino em espanhol para ambos os sentidos". Elas cumprem diferentes funções, como, por exemplo, o ajuste da ("hierarquia gramatical") relacionada à métrica e à retórica barrocas vinculadas à Decoratio, etapa retórica da construção do discurso musical em que se encontram as recomendações ao executante acerca da ornamentação. Sobre sua utilização, Butt (1990, p. 208-209) explica:

Ligaduras são mais freqüentemente associadas com os níveis de diminuição relativos ao Decoratio da música. [...] Na música para cordas a função de um ligado pode variar amplamente segundo um contexto, implicando acentuação, destaque da dinâmica ou a negação da pulsação esperada. [...] Alguns ligados podem ser vistos como motivos em si, se desenvolvendo enquanto a música avança; alguns impõem um ritmo que é diferente daquele da harmonia ou barra de compasso; alguns sublinham uma linha melódica que de outro modo estaria obscura na figuração; outras sugerem andamento e dinâmica. A música freqüentemente compreende a interação de vários elementos: ritmo métrico e harmônico, consistência figurativa e melódica e proporção. É freqüentemente a ambigüidade de qual elemento tem prioridade em qualquer trecho que dá à música sua qualidade particular. Ligados freqüentemente dão-nos um insight sobre como isso é conseguido, refletindo o momentum e simetria da música; às vezes eles executam várias funções interpretativas ao mesmo tempo(COSTA, 2012, p. 143).

A associação das ligaduras aos níveis de diminuição relativos à decoratio nos remete ao sentido de fragmentação, conforme observa Koellreutter (1979): "Pela diminuição, portanto, um som é desdobrado em vários sons e, assim, uma sequência de sons é decomposta em uma série de valores menores" (KOELLREUTTER, 1979, p. 1). As ligaduras presentes na sonata $n^{\circ} 2$ de Geminiani são notadas em lugares diferentes, se compararmos a pauta do violino com a tablatura do Cistre, diferenciando as articulações desses dois instrumentos, possivelmente adaptadas às possibilidades de cada 
A Adaptação da Sonata em Dó Menor para Cistre e Baixo Contínuo de Francesco Geminiani... Luciano Hercílio Alves Souto

um deles. Dessa forma, as duas maneiras como são notadas, tanto em um quanto em outro instrumento, podem ser cortejadas pelo transcritor para que uma ou mesmo ambas sejam consideradas no ato da transcrição.

\title{
1.2 Trinados
}

Sobre ornamentos como vibrato, arpejo, trinado, mordente e apojatura, Tyler (2011) considera:

\begin{abstract}
Os ornamentos são adornos para certas notas individuais de uma passagem. Eles eram genéricos e geralmente chamados "graças" na Inglaterra, ablimenti ou tremoli na Itália, agréements em fancês, e galanterias ou afetos na Espanha. toda uma gama de sinais de ornamentação é encontrada em tablaturas [para cordas dedilhadas]. Infelizmente, um sinal usado por um compositor para significar um tipo de ornamento foi frequentemente usado por outros compositores para significar outro tipo. Em alguns casos a aparência de um sinal de ornamento nem sequer significa um ornamento específico, mas apenas que um ornamento apropriado deve ser tocado naquele ponto da música! [...] A menos que um compositor tenha fornecido instruções específicas sobre os sinais utilizados para representar o ornamento que ele usou em seu livro (uma ocorrência rara), cabe ao instrumentista decidir quais [ornamentos] que ele [o compositor] pretendia quando usou um sinal em particular. (TYLER, 2011, p. 18).
\end{abstract}

O trinado simples pode ser observado nos compassos 2,4 e 8 do primeiro movimento da sonata $n^{\circ} \|$ de Geminiani, em que aparece representado pelo código " $t r$ ", posicionado acima da pauta do violino, não havendo qualquer informação em The Art of Playing the Guitar or Cittra (1760) em relação à sua execução. O autor apenas escreve: "Não devo, aqui, incomodar o leitor explicando os diferentes ornamentos, como trinado, pince, apojatura, etc., e sim remetê-los à instrução de um bom mestre ou ao engenho 
A Adaptação da Sonata em Dó Menor para Cistre e Baixo Contínuo de Francesco Geminiani... Luciano Hercílio Alves Souto

do executante." (GEMINIANI, 1760, p. 1, traduzido por NEVES, 2017, p. 468). No entanto, no A Treatise of Good Taste in the Art of Musik (1749), Tratado sobre o Bom Gosto na Música, Geminiani fornece instruções detalhadas sobre sua execução ao violino: “O trinado simples é apropriado para movimentos rápidos, e pode ser realizado sobre qualquer nota, observando-se que se deve prosseguir, imediatamente, à nota seguinte" (GEMINIANI, 1749, p. 2, traduzido por NEVES, 2017, p. 184). Em sua tabela de exemplos musicais encontramos o seguinte exemplo ilustrativo de sua execução, reproduzido na Figura 5.

Figura 5 - Elementos para tocar e cantar com bom gosto

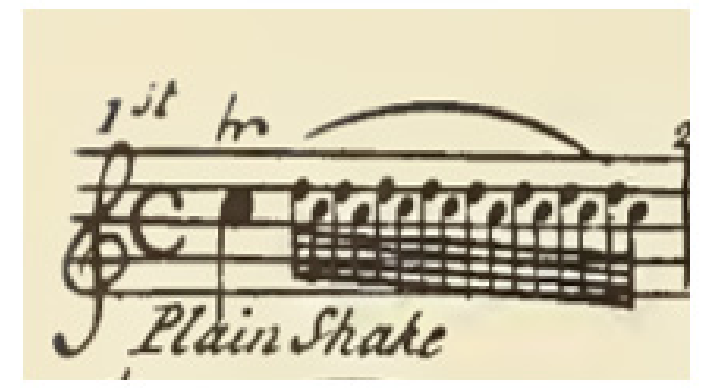

GEMINIANI, Francesco. A Treatise of Good Taste in the Art of Musik, 1749, p. 6, exemplo 1. Elementos para tocar e cantar com bom gosto.

Sobre sua execução ao cistre, Silva Leite fornece as seguintes instruções em seu "Estudo de Guitarra” (1795), Figura 6. 
A Adaptação da Sonata em Dó Menor para Cistre e Baixo Contínuo de Francesco Geminiani... Luciano Hercílio Alves Souto

\section{Figura 6 - Regra XVIII, parte 1}

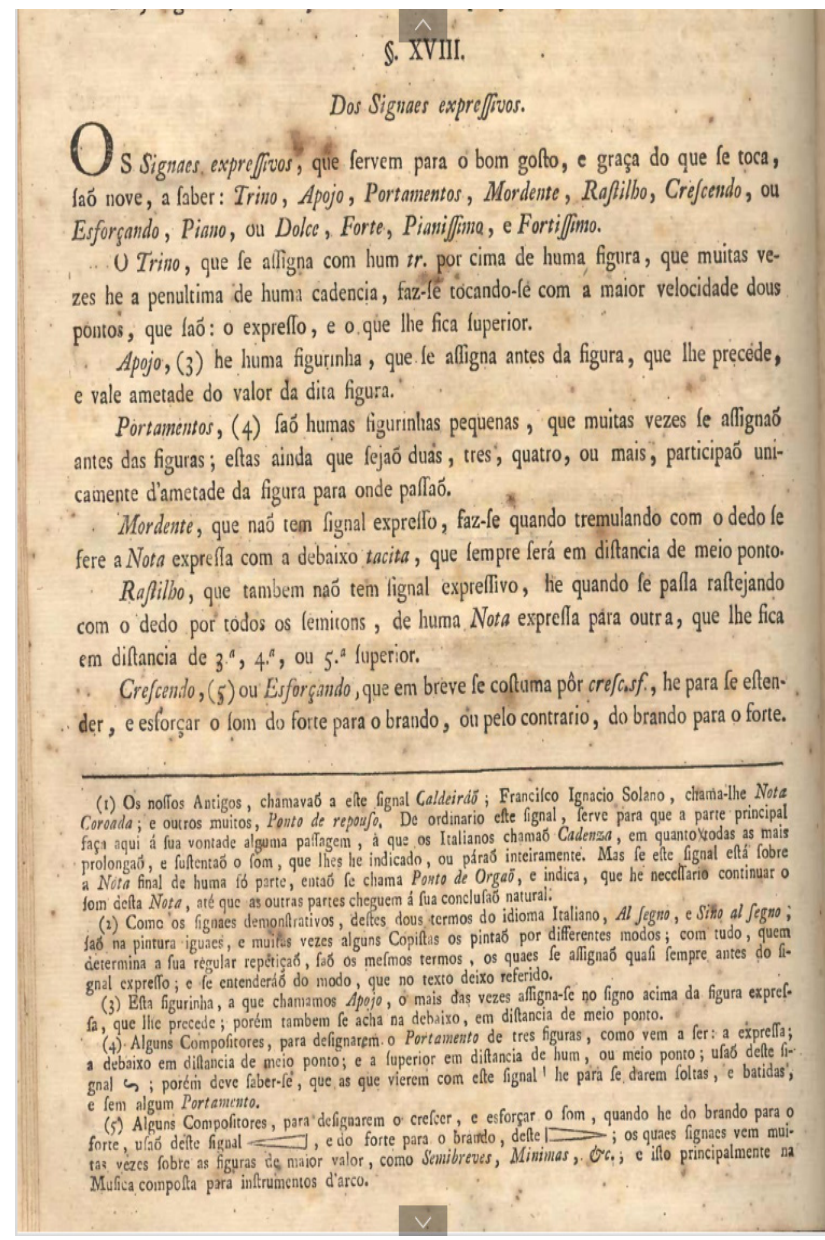

LEITE, Antonio da Silva. Estudo de Guitarra, 1795, p. 16. Regra XVIII, parte 1. "Dos signos expressivos".

Ambos os autores descrevem o mesmo procedimento técnicoinstrumental quanto à mecânica da mão esquerda, diferenciandose em relação aos locais apropriados para a sua utilização. Geminiani (1760) recomenda seu uso em movimentos rápidos, podendo ser empregado em qualquer nota, e Silva Leite (1795) vincula o seu uso principalmente a finalizações cadenciais. Sua utilização pelos instrumentos históricos da família das guitarras entre os quais se situa a viola (NOGUEIRA, 2008) é abordada por Guerau (1697), que fornece instruções sobre sua execução acompanhadas de codificação específica: 
A Adaptação da Sonata em Dó Menor para Cistre e Baixo Contínuo de Francesco Geminiani... Luciano Hercílio Alves Souto

Você encontrará também uma pequena linha, com dois pequenos pontos, desta forma, (\%) que na Itália assinalam com um $\mathrm{T}$, e dois pontos, que se chama, Trino, ou ligado, que se executa com a mão esquerda, colocando o dedo conveniente no traste assinalado pelo número, e com outro dedo da mesma mão ferindo a corda, sem parar, dois trastes; ou um mais adiante, conforme prendeste o ponto. (GUERAU, 1694, p. 4) (tradução nossa).

\subsection{Apojatura Superior}

Se tratando da apojatura superior, encontrada no compasso 32 do terceiro movimento (Allegro Cantábile), na Figura 7, Geminiani (1749) escreve:

A apojatura superior deve expressar amor, afeição, prazer etc. Deve ser realizada longa, atribuindo-se a ela mais da metade da extensão ou do tempo da nota a que pertence, observando para que se aumente o som gradativamente e, aproximandose do fim, para que se force um pouco o arco. Se for realizada curta, perderá muito das qualidades citadas, mas sempre terá um efeito prazeroso e pode ser adicionada a qualquer nota que quisermos. (GEMINIANI, 1749, p. 2, traduzido por NEVES, 2017, p. 184-185). 
A Adaptação da Sonata em Dó Menor para Cistre e Baixo Contínuo de Francesco Geminiani... Luciano Hercílio Alves Souto

Figura 7 - Exemplo musical II

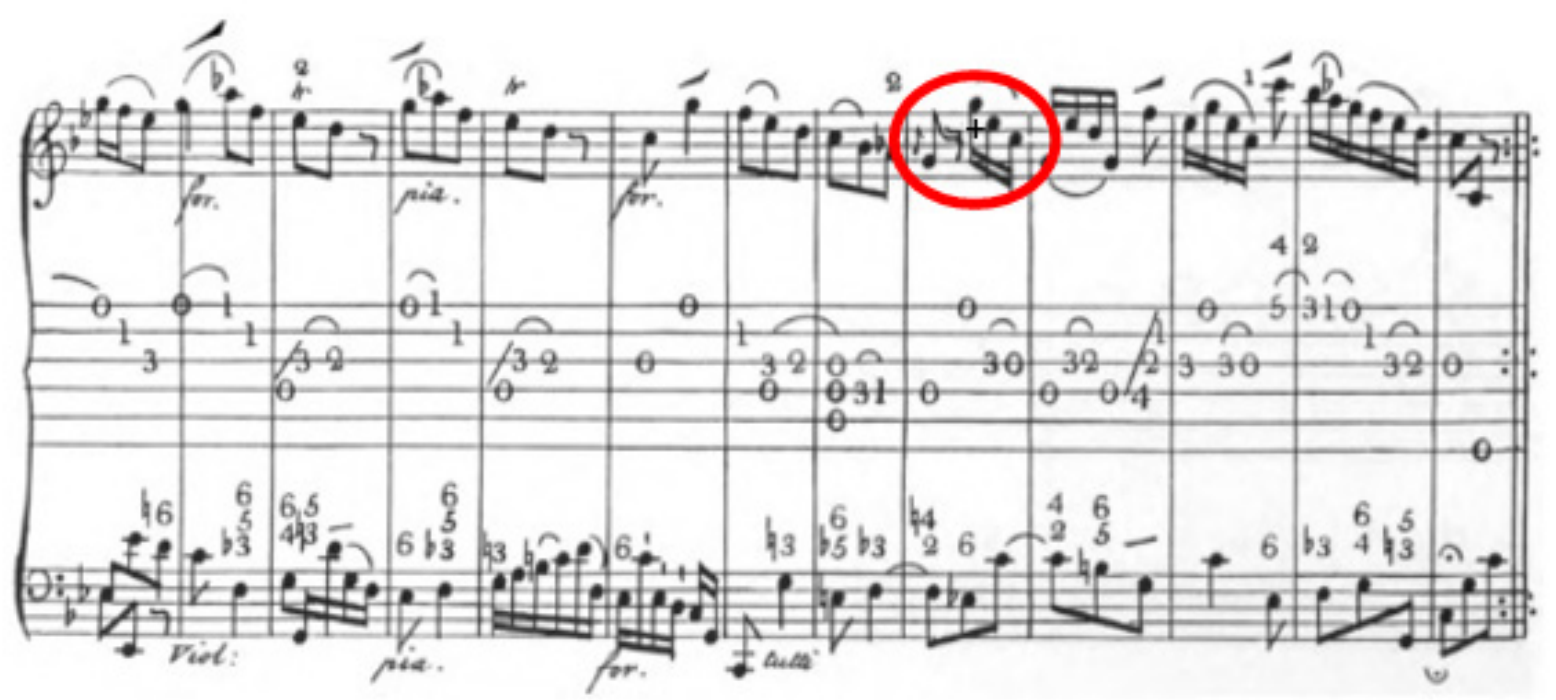

GEMINIANI, Francesco. The Art of Playing the Guitar or Cittra, 1760, p. 11. Exemplo I/ em dó menor, terceiro movimento, compassos 24-36.

Embora Geminiani trate da realização da apojatura superior ao violino, a observação do compositor em relação à sua função expressiva no sentido de "expressar amor, afeição, prazer etc.", bem como as observações relacionadas à sua duração, devendo "ser realizada longa, atribuindo-se a ela mais da metade da extensão ou do tempo da nota a que pertence", atendem igualmente as cordas dedilhadas. Isso é possível porque tais observações correspondem a características retórico-musicais cujos recursos técnico-idiomáticos adequados à expressão variam conforme o instrumento musical empregado. No que concerne à execução da apojatura superior em instrumentos da família das guitarras, Tyler (2011) afirma:

A appoggiatura, chamada esmorsata, apoyamento ou ligadura em fontes espanholas e cheute em francês. [...] a apoggiattura descendente é tocada com o ataque começando em uma nota acima da nota principal (escrita), e, em seguida, puxando-a rapidamente para a principal; [...] O sinal para o appoggiatura descendente é geralmente uma linha pequena, horizontal e curva acima ou abaixo da nota principal, embora alguns 
A Adaptação da Sonata em Dó Menor para Cistre e Baixo Contínuo de Francesco Geminiani... Luciano Hercílio Alves Souto

compositores usavam um $x$ pequeno e outros um t pequeno. (TYLER, 2011, p. 20), (tradução nossa).

\subsection{O Pincé}

O pincé, para Geminiani:

É apropriado para expressar diversas paixões. Por exemplo, se realizado com força e continuamente longo, expressa fúria, raiva, determinação etc. Se tocado menos forte e mais curto, expressa júbilo, satisfação etc. Entretanto, se o tocarmos muito suave e fizermos um crescendo, o pincé pode, então, denotar horror, medo, pesar, lamentação etc. Se tocado de forma curta e com um crescendo delicado, pode expressar afeição e deleite. (GEMINIANI, 1749, p. 3, traduzido por NEVES, 2017, p. 188).

O exemplo de sua execução ao violino constitui o $13^{\circ}$ ornamento da tabela de ornamentos do Tratado sobre o Bom Gosto na Música (1749), Figura 8.

Figura 8 - A Treatise of Good Taste in the Art of Musik, exemplo 13

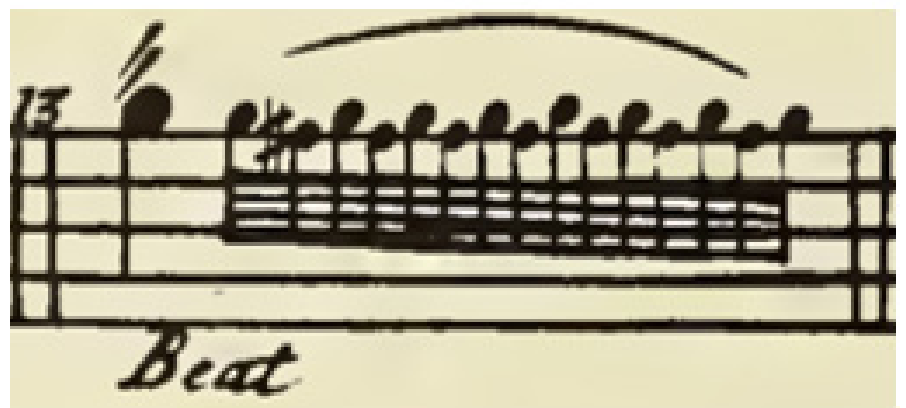

GEMINIANI, Francesco. A Treatise of Good Taste in the Art of Musik, 1749, p. 06. Elementos para se tocar com bom Gosto, exemplo XIII.

Se comparado ao trinado simples, que começa da nota ascendente à nota real por grau conjunto, o pincé começa na própria nota real e realiza o mesmo movimento por grau conjunto até a próxima nota, descendentemente. Portanto, se serve da 
A Adaptação da Sonata em Dó Menor para Cistre e Baixo Contínuo de Francesco Geminiani... Luciano Hercílio Alves Souto

mesma mecânica básica do trinado simples e, desta forma, tal qual o trinado, seu padrão de execução conforme demonstrado por Geminiani, pode ser adaptado para a viola de arame, da mesma forma do trinado simples.

\subsection{Dinâmica}

No que concerne aos signos dinâmicos utilizados por Geminiani em sua Sonata $\mathrm{n}^{\circ} \mathrm{II}$, podemos encontrar o Crescendo, o Diminuendo, o Forte e o Piano, sobre os quais escreve o autor: "Esses dois elementos [Crescendo e Diminuendo] podem ser realizados um após o outro. Produzem grande beleza e variedade na melodia e, quando empregados alternadamente, são próprios a qualquer expressão ou compasso". E sobre o Piano e o Forte: "Ambos são extremamente necessários para expressar a intenção da melodia e, como toda boa música deve ser composta imitando um discurso, esses dois ornamentos são designados a produzir os mesmos efeitos que um orador produz ao elevar e ao diminuir sua voz." (GEMINIANI, 1749, p. 3, traduzido por NEVES, 2017, p. 186-187). Tais recursos expressivos podem ser visualizados no terceiro movimento "Allegro Cantábile", compassos 15,16, 25, 27 e 29, representados na Figura 9. 
A Adaptação da Sonata em Dó Menor para Cistre e Baixo Contínuo de Francesco Geminiani... Luciano Hercílio Alves Souto

Figura 9 - Exemplo musical II
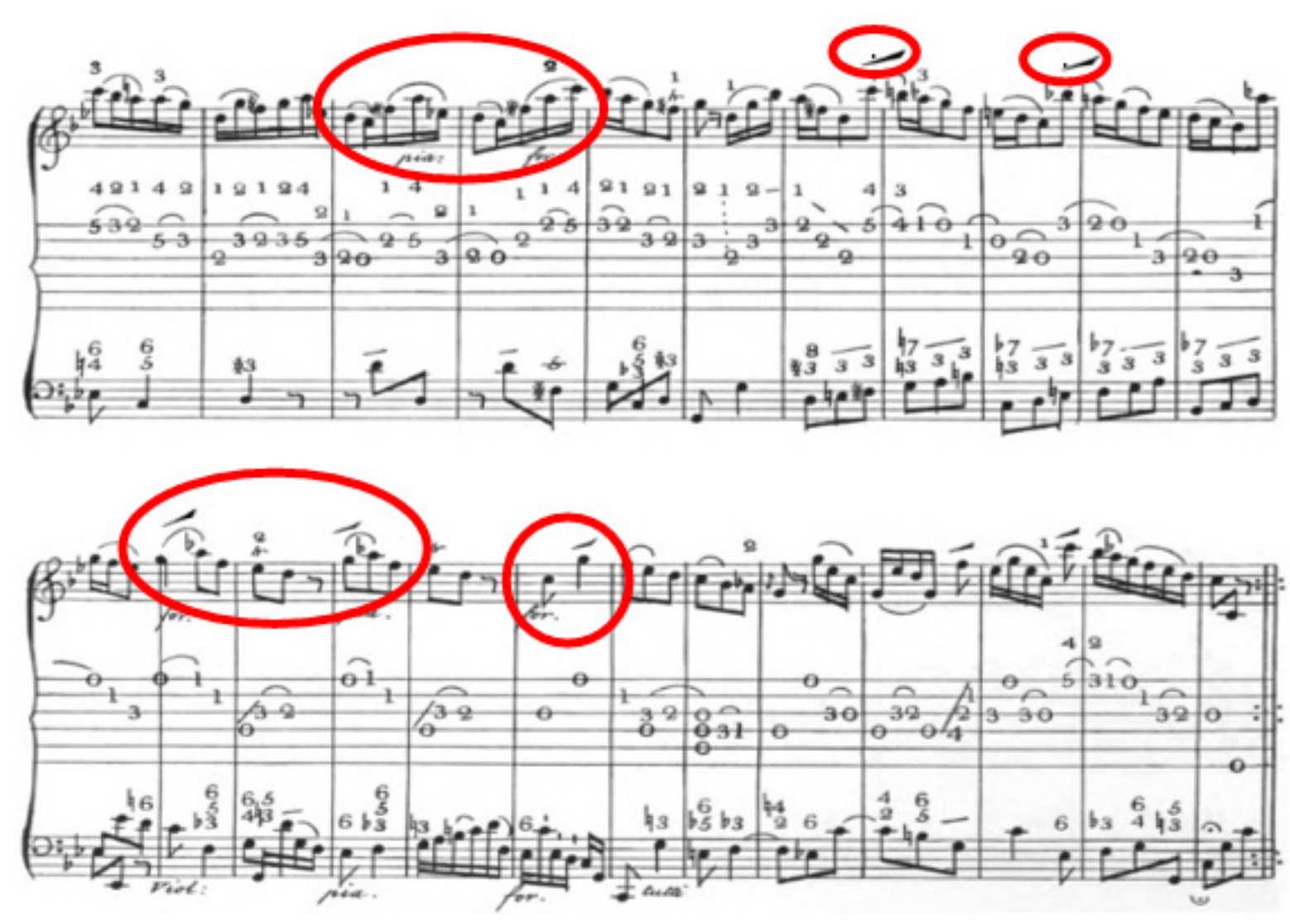

GEMINIANI, Francesco. The Art of Playing the Guitar or Cittra, 1760, p. 11.

Exemplo Il em dó menor, terceiro movimento, compassos 13 a 36.

Os códigos notacionais do forte e do piano aparecem escritos verbalmente, for. e pia., abaixo das linhas de violino e baixo contínuo. Dos signos correspondentes ao crescendo e ao decrescendo, apenas o primeiro aparece notado em toda a sonata e pode ser visualizado a partir dos compassos 19-20, representados por uma linha oblíqua crescente da esquerda para a direita.

\section{O Processo de Transcrição}

Para transcrever a sonata $\mathrm{n}^{\circ}$ II para viola de arame recorremos a dois procedimentos integrados: "transcrição comum" e "afinação para cada peça", sobre os quais Cardoso (2014) escreve: 
A Adaptação da Sonata em Dó Menor para Cistre e Baixo Contínuo de Francesco Geminiani... Luciano Hercílio Alves Souto

Transcrição comum, éa transcrição direcionada paraviolonistas, escrita em partitura, em geral apenas com as articulações e ligados que são executáveis no violão. As principais ferramentas deste método são a mudança de tonalidade da peça para uma tonalidade que melhor se adapte ao violão e transposição de oitava de baixos que estão além da tessitura deste instrumento. [...] Uma terceira categoria da abordagem da transcrição, que surge dos desdobramentos do método anterior, é a afinação do violão adaptada para cada peça. Esse conceito parte da constatação empírica de que algumas peças específicas têm sua execução técnica facilitada ou viabilizada pela mudança na afinação de até três cordas. (CARDOSO, 2014, p. 37). (grifo nosso).

A partir dos procedimentos elencados por Cardoso (2014), estabelecemos os seguintes critérios para a transcrição da Sonata: 1- escrita em partitura, com articulações e ligados executáveis à viola, 2 - mudança de tonalidade e 3- mudança de afinação, na medida em que a adaptação aqui proposta envolve as mesmas implicações dos procedimentos de transcrição analisados por Cardoso (2014).

\subsection{Mudança de Tonalidade}

A integração de procedimentos da transcrição do tipo "comum" e da "afinação para cada peça" (CARDOSO, 2014) possibilita a transposição da tonalidade original de dó menor para ré menor, dispensa o uso excessivo de pestanas e elimina a necessidade de utilização do Capotasto, recursos esses necessários à preservação da tonalidade original. No entanto, a opção pela tonalidade de ré menor resulta em uma alteração inevitável da digitação e das articulações da escrita original. 
A Adaptação da Sonata em Dó Menor para Cistre e Baixo Contínuo de Francesco Geminiani... Luciano Hercílio Alves Souto

\subsection{Mudança de Afinação}

Considerando-se a possibilidade de mudança da afinação da viola como recurso transcricional do tipo "afinação por peça", recorremos a Sanz (1674) que, ao manifestar suas preferências pelos recursos de afinação adotados em relação ao encordoamento da guitarra barroca, escreve:

Ao encordoar há uma variedade [de opções], porque em Roma somente encordoam a guitarra com cordas finas, sem colocar nenhum bordão, nem na quarta, nem na quinta [ordem]. $\mathrm{Na}$ Espanha, ao contrário; pois alguns utilizam bordões na quarta e outros, dois [bordões] na quinta e ao menos comumente um em cada ordem. Estes dois modos de encordoar são bons, mas para diversos efeitos, porque aquele que tocar a guitarra para fazer música ruidosa, [...] é melhor com bordões na guitarra do que sem eles; mas se alguém quer pontear com primor e doçura, e usar das campanelas, não falam bem os bordões; apenas cordas delgadas nas quartas e quintas, como tenho grande experiência; e é esta a razão porque para fazer "trinos", "extrasinos" e demais "galanterias" de mão esquerda, se há bordão, impede por ser uma corda grossa e outra delgada, além de não poder pisar com igualdade [em ambas as cordas de mesma ordem]. (SANZ, Instrucción de musica sobre la guitarra española, tomo 1, prefácio, 1675). (tradução nossa). 
A Adaptação da Sonata em Dó Menor para Cistre e Baixo Contínuo de Francesco Geminiani... Luciano Hercílio Alves Souto

Figura 10 - "Regla primera"

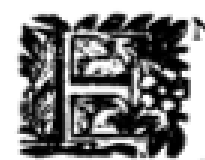

el encordar ay variedad, porque en Roma aquellos Maeftros folo encuerdan la Guitarra con cuerdas delgadas, fin poner ningun bordon, ni en quarta, ni en quinta. En Efpańa es al contrario, pues algunos vfan de dos bordones en la quirta, y otros dos en la quinta, y à lo menos, como de ordinario, vno en cada orden. Eftos dos modos de encordar fon buenos, pero para diverfos efectos, porque el que quiere tańer Guiturta para hazer mufica ruidola,ò acompańa fe el baxo cen algun tono , ò fonada, es mejor con bordones la Guitarra, que fin ellos i pero fi alguno quiera puntear con primor, $y$ dulçuta, y viar de las campanelas, que es cl modo moder no con que aora fe compone, no falen bien los bordones, fino folo cuerdas delgadas, alsi en las Tow. $\mathrm{s}$.

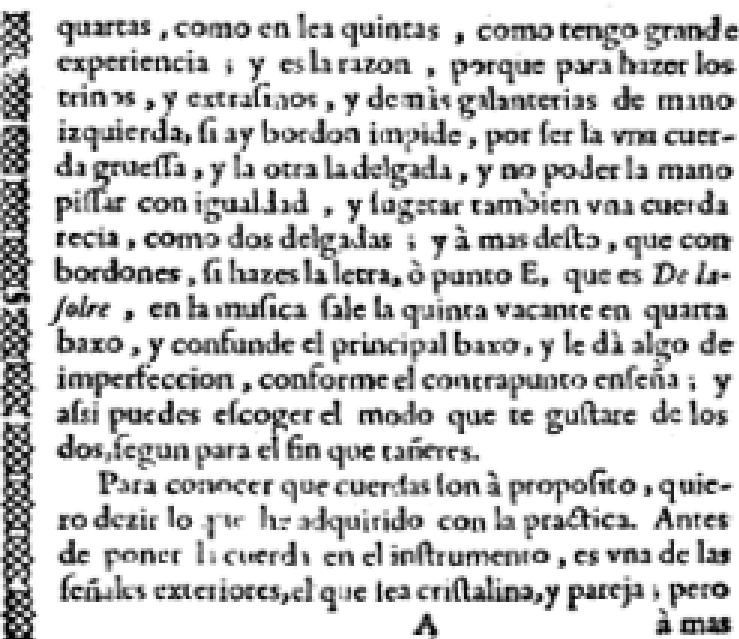

SANZ, Gaspar. Instrucción de musica sobre la guitarra española, 1675, p. 1, tomo 1 Regra primeira, de encordoar.

Sanz trata de afinações reentrantes, comuns em guitarras e alaúdes dos séculos XVII e XVIII, cuja inserção de notas agudas nos lugares dos bordões da quarta e quinta ordens de cordas resultavam em um efeito denominado pelos italianos como Campanellas, que normalmente eram utilizadas de maneira combinada e ou intercalada com ornamentos como ligaduras, "trinos, extrasinos e demais galanterias de mão esquerda" (SANZ, 1674). Sobre o seu efeito, Tyler (2011) explica:

O uso de efeitos de harpa ou sino em passagens de escala é outro idioma importante da guitarra. Não existe um termo amplo para esse efeito, que os italianos chamavam campanela, mas o guitarrista espanhol Gaspar Sanz, que adotou a técnica italiana, chamou de campanelas (sininhos). É realizada tocando-se cada nota de uma escala (ou outra passagem melódica) em uma ordem diferente e empregando o maior número possível de cordas soltas, permitindo assim que cada nota da escala possa soar pelo maior tempo possível. O efeito é semelhante a tocar uma escala rápida nas cordas soltas de uma harpa sem amortecer nenhuma delas; a sucessão das durações das notas anteriores se mistura com as das notas posteriores (TYLER, 2011, p. 24). 
A Adaptação da Sonata em Dó Menor para Cistre e Baixo Contínuo de Francesco Geminiani... Luciano Hercílio Alves Souto

Tyler (2011) identifica as campanelas como recursos técnicoidiomáticos únicos dos instrumentos que utilizam em sua encordatura a afinação reentrante, utilizada para se executar o repertório cortês em estilo ponteado, dentro do qual podemos reconhecer as sonatas para cistre e baixo contínuo de Gemminiani (1760). Tal reconhecimento decorre do fato de que no frontispício de The Art of Playing the Guitar or Cittra (1760) podemos encontrar a seguinte dedicatória: "Mui humildemente dedicado à CONDESSA de CHARLEVILLE" (traduzido por NEVES, 2017, p. 146). Tal aspecto constitui o primeiro indício do vínculo dessa produção de Geminiani com o ambiente cortês da Inglaterra do século XVIII, acrescentando-se a este aspecto sua tablatura, que demonstra uma textura homofônica passível de execução apenas pela técnica do ponteado, bem como a estrutura e a forma musicais de suas sonatas, constituídas por três a cinco movimentos de caráter e andamento contrastantes, característicos desse estilo composicional. Dessa forma, optamos por utilizá-las a partir de uma encordatura que permitisse incorporá-las à sonata $n^{\circ} \|$ de Geminiani (1760), discutida por este trabalho. Para isso, partimos da afinação para a viola de Ribeiro (1789), representadas nas figuras 11 e 12, e substituímos o bordão da quinta ordem por sua oitava superior, caracterizando assim a afinação reentrante descrita por Sanz (1674) para a guitarra barroca, representada na Figura 13. 
A Adaptação da Sonata em Dó Menor para Cistre e Baixo Contínuo de Francesco Geminiani... Luciano Hercílio Alves Souto

\section{Figura 11 - Estampa I}

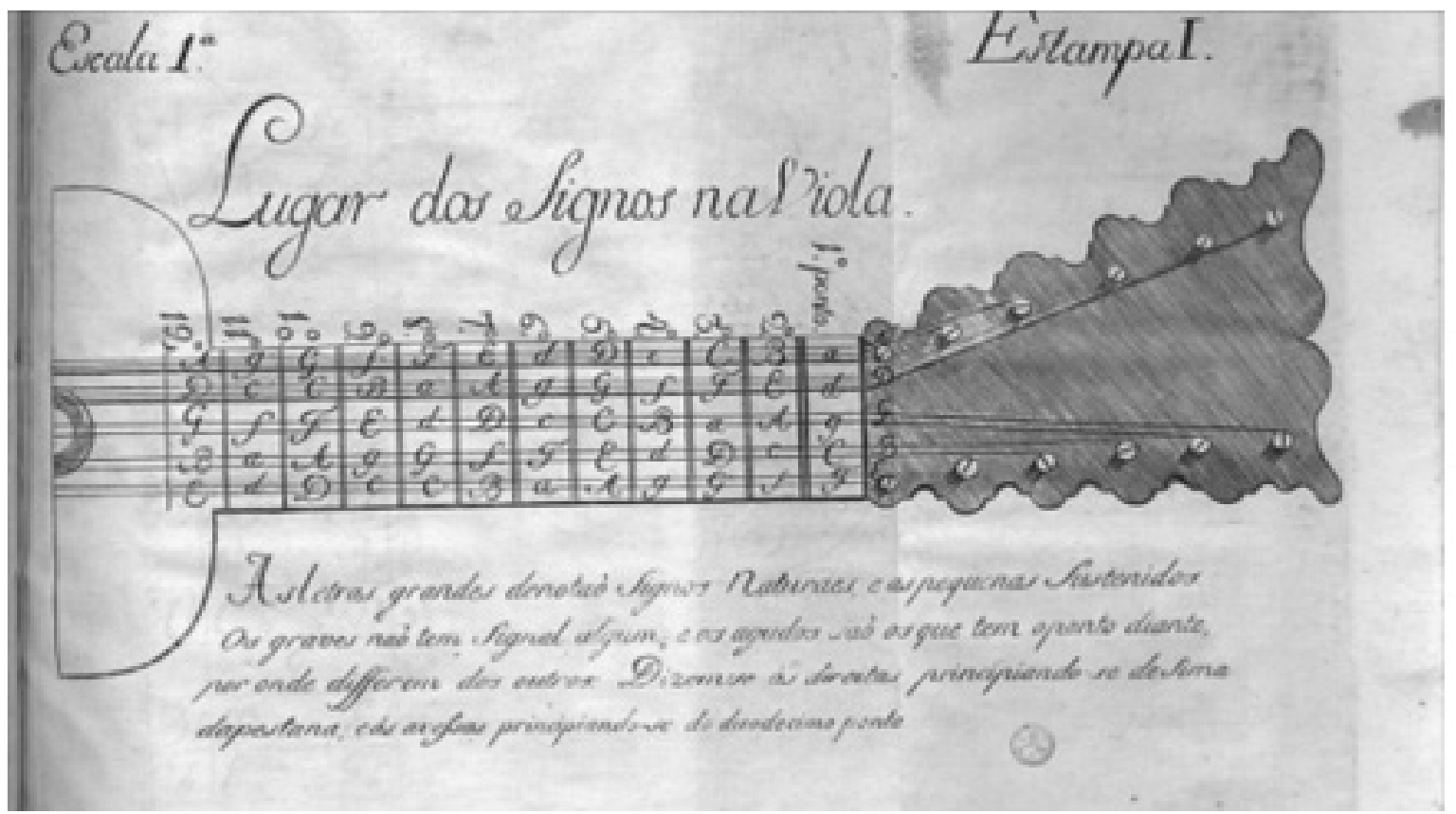

RIBEIRO, Manuel da Paixão. Nova Arte de Viola, 1789, p. 53. Estampa I. "Lugar dos Signos na Viola".

Figura 12 - Afinação com bordão

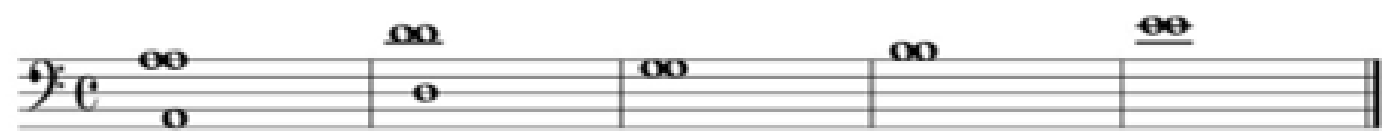

RIBEIRO, Manuel da Paixão. Nova Arte de Viola, 1789, p. 53.

Afinação da viola de arame com bordão oitavado na quinta ordem. Transcrição: Nogueira, 2008.

\section{Figura 13 - Afinação reentrante}

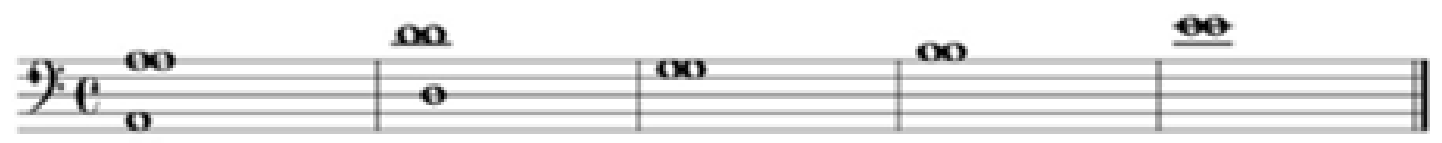

(8)

RIBEIRO, Manuel da Paixão. Nova Arte de Viola, 1789, p. 53. Afinação reentrante da viola de arame, com uníssono na quinta ordem. Transcrição nossa.

A escolha pela tonalidade de ré menor para a transcrição aqui discutida propicia a inserção de recursos expressivos técnicoidiomáticos característicos do repertório, dos instrumentos e das práticas musicais da época à sonata em dó menor de Geminiani, 
A Adaptação da Sonata em Dó Menor para Cistre e Baixo Contínuo de Francesco Geminiani... Luciano Hercílio Alves Souto

assim como conserva as notas musicais em suas oitavas originais, dispensando qualquer necessidade de se oitavarem intervalos ou frases, conforme demonstra o exemplo da Figura 13.

Figura 14 - Sonata $\mathrm{n}^{\circ}$ II para cistre e baixo contínuo

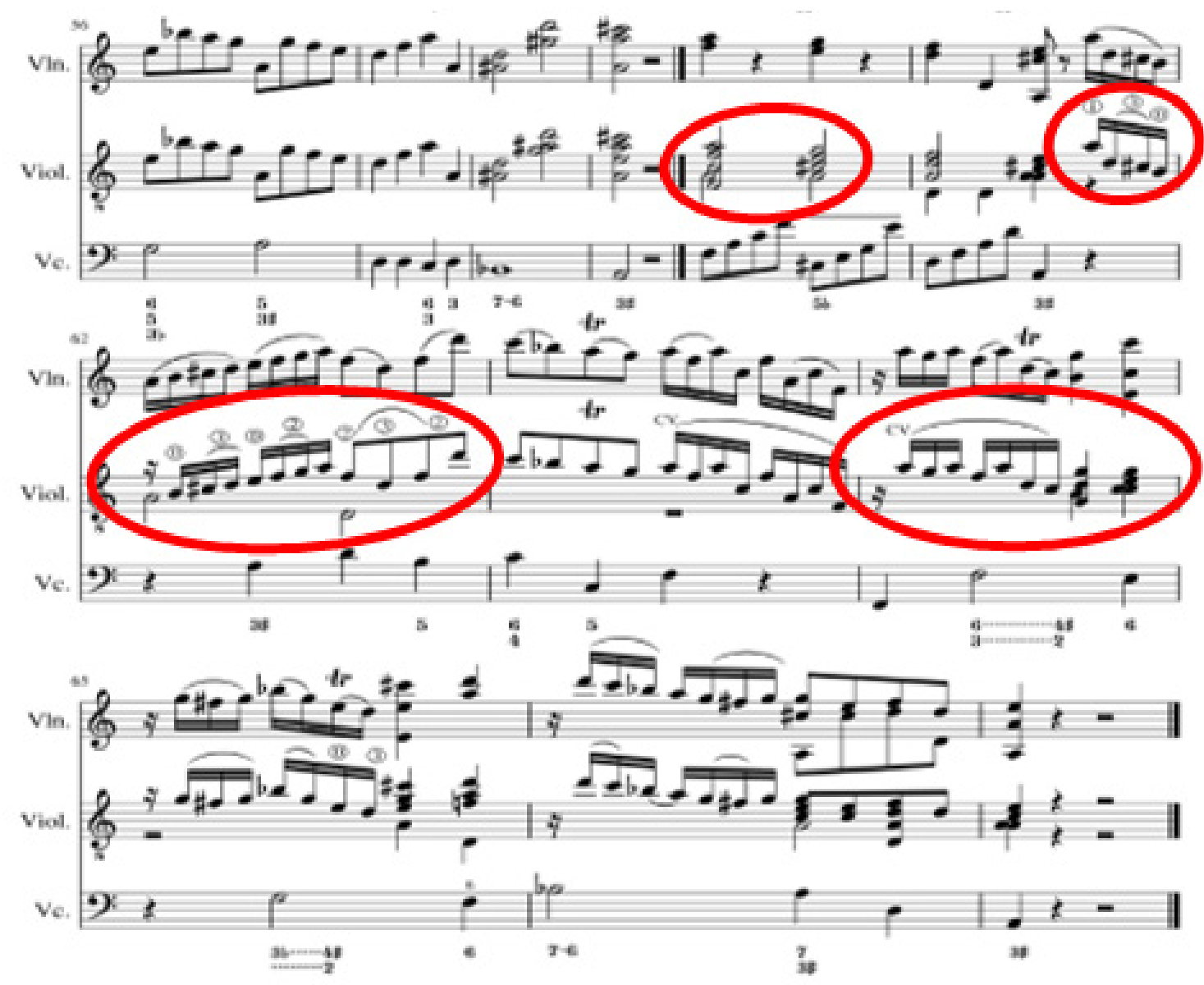

GEMINIANI, Francesco. $2^{\circ}$ movimento, compassos 60 a 67, The Art of Playing the Guitar or Cittra, 1760, p. 10. Sonata $n^{\circ} / l$ para cistre e baixo contínuo, $2^{\circ}$ movimento, compassos 60 a 67, Transcrição nossa.

A pauta central correspondente à parte de viola de arame apresenta algumas notas com as hastes para baixo, que são tocadas na quinta ordem reentrante da viola. A utilização das campanelas intercaladas com as ligaduras pode ser visualizada nos compassos 61 e 62. As notas que não apresentam ligaduras curtas de duas ou três notas são tocadas em cordas soltas, indicadas com o algarismo 0 dentro do círculo, formando a campanela com 
A Adaptação da Sonata em Dó Menor para Cistre e Baixo Contínuo de Francesco Geminiani... Luciano Hercílio Alves Souto

a próxima nota tocada em corda presa e a campanela entre essas duas cordas (solta e presa). As ligaduras longas correspondem à ressonância de todas as notas compreendidas por elas, sob a indicação de pestana por meio da letra " $\mathrm{C}$ ", acompanhada da casa no braço do instrumento em que é montada a pestana. No caso dos compassos 62 e 64 significa $5^{a}$ casa. Portanto, "CV" significa pestana na casa 5.

\subsection{Preenchimentos Harmônicos}

Quanto aos preenchimentos harmônicos, Costa (2012) estabelece alguns critérios a partir da análise de obras para violino transcritas para alaúde por Bach e seus contemporâneos, que podem subsidiar a transcrição da tablatura do cistre para viola de arame na medida em que apresentam implicações semelhantes aos procedimentos empregados no processo aqui discutido. Segundo o autor,

Quanto aos preenchimentos harmônicos, concluímos que nos pontos de repouso, onde no original há apenas a nota fundamental, ou a fundamental dobrada ou a fundamental dobrada mais a quinta do acorde (no original de violino são raros os casos em que há a fundamental dobrada mais a terça do acorde), a vasta maioria dos acordes é preenchida para completar a tríade e com a oitava dobrada, formando acordes de quatro vozes. Nos finais de cada sessão e nas cadências intermediárias, todos os acordes de resolução são completados. Diferentemente da escrita para violino e para violoncelo, que muitas vezes apresentam os acordes com fundamental dobrada, tendo apenas a quinta como preenchimento, as transcrições não apresentam nenhum acorde com essa configuração, ou seja, todos os acordes têm a terça (a ênfase aqui é necessária, pois a ignorância das práticas de preenchimento de acordes faz com que muitos violonistas tratem com preciosismo os acordes sem terça ou os pontos de resolução cadenciais que apresentam 
A Adaptação da Sonata em Dó Menor para Cistre e Baixo Contínuo de Francesco Geminiani... Luciano Hercílio Alves Souto

apenas a fundamental dobrada, como é o caso das resoluções em Ré menor e Dó menor do Adagio da Sonata Prima) (COSTA, 2012, p. 135-136).

Com base em tais considerações, podemos confrontar as mesmas questões tratadas por Costa (2012) na escrita harmônica da pauta do violino e da tablatura do cistre da sonata $\mathrm{n}^{\circ} \| \mathrm{l}$ de Geminiani. Esse procedimento é utilizado pelo próprio Geminiani que, em sua escrita harmônica, utiliza acordes mais cheios na tablatura do cistre do que na partitura do violino, possivelmente aproveitando as características harmônicas mais acentuadas do cistre. Dessa forma, utilizando o mesmo procedimento, realizamos alguns preenchimentos harmônicos para a transcrição da parte do cistre para a viola, pelos mesmos motivos.

\section{Considerações finais}

Concluímos que a mudança de meios, notacional (tablatura para partitura) e instrumental (Cistre para a Viola), envolveu a necessidade de se avaliarem critérios para a transcrição do ritmo, ausente na tablatura, para o qual utilizamos a escrita do violino como referência, considerando recomendação do autor nesse sentido: "No que concerne ao tempo e ao valor das notas, a parte do violino deve apenas ser observada" (GEMINIANI, 1760, p. 1). Um dos elementos que adaptamos às possibilidades da viola dentro de uma digitação viável à execução da Sonata foram as ligaduras curtas, de duas notas, e longas, de três ou quatro notas. As ligaduras de duas notas se referem ao mesmo procedimento descrito por Geminiani para o Cistre: "Quando um traço (curvo) é posicionado sobre dois ou mais números, apenas a primeira [nota] deve ser golpeada, porque os dedos, na passagem de uns para outros, produzirão o som" (GEMINIANI, 1760, p. 1). No caso das ligaduras longas, estas significaram a sustentação do som de cada nota sobrepondo-se à próxima, ao longo de três ou quatro notas na medida em que nem sempre a sequência de notas sob 
A Adaptação da Sonata em Dó Menor para Cistre e Baixo Contínuo de Francesco Geminiani... Luciano Hercílio Alves Souto

a ligadura foi possível de ser realizada em uma mesma corda. Tal procedimento revelou elementos harmônicos e melódicos invisíveis na tablatura, como, por exemplo, a linha melódica descendente descrita pelas notas ré, dó, si e lá dos compassos 49 a 52, acompanhadas pela sequência harmônica descrita pelos acordes de fá maior, mi menor, ré menor e dó maior. Tais estruturas foram reveladas no plano da escrita em decorrência da mudança de meio notacional e foram evidenciadas pela articulação resultante das ligaduras de sustentação harmônica do arpejo de três notas sobre a fundamental e a terça dos respectivos acordes, sob a linha melódica da transcrição. Portanto, a avaliação desses aspectos, entre outros ao longo deste texto, propiciou a reflexão fundamentada em fontes primárias e secundárias, resultando em critérios transcritivos sólidos o suficiente para que se desdobrassem em performances dessa obra à viola de arame, contextualizadoras do pensamento musical de Geminiani em relação à prática instrumental de sua época.

\title{
Referências
}

\author{
CARDOSO, R. C. Repertório barroco e suas possibilidades ao \\ violão: aspectos teóricos e métodos transcritivos a partir das \\ cordas dedilhadas. Dissertação de Mestrado. Instituto de Artes da \\ Universidade Estadual Paulista Júlio de Mesquita Filho, 2014. São Paulo: \\ UNESP, 2014. 166 p. Disponível em: https://repositorio.unesp.br/ \\ handle/11449/110648. Acesso em: 07 jun. 2020.
}

COSTA, G. S. Seis sonatas e partias para violino solo de J. S. Bach ao violão: fundamentos para a adaptação do ciclo. Tese de doutorado. Escola de Comunicação e Artes da Universidade de São Paulo, 2014. São Paulo, 2014. 192 p.

GEMINIANI, Francesco. The Art of Playing the Guitar or Cetra. Edição fac-símile. Edimburgo: Robert Bremner,1760. 51 p.

GEMINIANI, Francesco. A treatrise of good taste in the art of musik. Edição fac-símile. London, 1749. 30 p. 
A Adaptação da Sonata em Dó Menor para Cistre e Baixo Contínuo de Francesco Geminiani... Luciano Hercílio Alves Souto

GUERAU. Francesco. Poema Harmônico. Edição fac-símile. London: Tecla Editions, 1974. 70 p.

KOONCE, F. Johann Sebastian Bach The Solo Lute Works. 2 Edição. San Diego, Califórnia. Neila A. Kjos Music Company. 2002. 143 p. LEITE, António da Silva. Estudo de guitarra, em que se expoem o meio mais fácil para aprender a tocar este instrumento... Porto: Officina Typografica de Antonio Alvarez Ribeiro. 1795. 38 p.

\section{LINDE, H. M. Pequeno Guia para a Ornamentação da Música} do Barroco (séc. XVI-XVIII). tradução: H.J. Koellreutter, São Paulo: Ricordi,1979. 44 p.

NEVES, M. V. S. H. Francesco Geminiani (1687-1762): Comentários e tradução da obra teórica completa. Dissertação de Mestrado. Escola de Comunicação e Artes da Universidade de São Paulo, 2017. São Paulo: USP, 2017. 531 p. Disponível em: https://www.teses. usp.br/teses/disponiveis/27/27157/tde27092017101128/publico/ MarcusViniciusSantAnnaHeldNeves.pdf . Acesso em: 07 jun. 20. NOGUEIRA, G. G. P. A viola com anima: uma construção simbólica. Tese de Doutorado. Escola de Comunicação e Artes da Universidade de São Paulo, 2008. São Paulo: USP, 2008. 233p. Disponível em: http:// www.teses.usp.br/teses/disponiveis/27/27154/tde-15052009-140811/ pt-br.php. Acesso em: 07 jun. 20.

NOGUEIRA, G. G. P. A viola e suas metalinguagens: notação do gesto e aprendizado não formal. Revista Tulha, Ribeirão Preto, v. 2, n. 1, p. 119-143, 2016.

RIBEIRO, M. P. Nova Arte de Viola. Real Oficina da Universidade de Coimbra. Coimbra, Portugal, 1789.

TYLER, J; SPARKS, P. The guitar and It's Music: From de Renaissance to the Classical Era. Oxford: Early Music Series, 2002. 322 p.

TYLER, J; SPARKS, P. A Guide to Playing the Baroque Guitar. Indiana: University Press, 2011. 176 p. 
A Adaptação da Sonata em Dó Menor para Cistre e Baixo Contínuo de Francesco Geminiani... Luciano Hercílio Alves Souto

\section{Agradecimentos}

À Lilian e Joanna...

À Universidade do Estado do Amazonas, pelo financiamento desta pesquisa e pelas condições acadêmicas necessárias à elaboração do projeto inicial desta pesquisa por meio do Laboratório de Musicologia e História Cultural.

À Universidade Estadual Paulista Júlio de Mesquita Filho, UNESP - Instituto de Artes, Programa de Pós-graduação em Música, por me receber como Pós-doutorando em 2020 e propiciar as condições acadêmicas necessárias à realização deste trabalho.

À Profa. Dra. Gisela Gomes Pupo Nogueira, pela supervisão desta pesquisa. 